\title{
Identification by monoclonal antibodies of serotype D strains of Pasteurella multocida representing various geographic origins and host species
}

\author{
M. VASFI MARANDI, J. HAREL and K. R. MITTAL \\ Département de Pathologie et Microbiologie, Faculté de Médécine Vétérinaire, Université de Montréal, CP \\ 5000 Saint-Hyacinthe, Québec J2S 7C6, Canada
}

\begin{abstract}
Two outer-membrane proteins (OMPs) of Pasteurella multocida serotype D, designated H and $W$, possess potentially important serotype $D$-specific antigens. Antigenicity as well as toxigenicity of 55 strains of $P$. multocida representing various serotypes, geographic origins and host species were studied by SDS-PAGE, enzyme-linked immunosorbent assay (ELISA), immunoblot and polymerase chain reaction (PCR) assays. Based on the electrophoretic mobility of protein $H$, different OMP patterns were observed within different capsular serotypes. Three monoclonal antibodies (MAbs) designated MT1, MT2 and MT3 were produced against $H$ and $W$ proteins of $P$. multocida in BALB/c mice. MAbs MT2 and MT3 reacted with two distinct epitopes on W protein of serotype $D$ in competitive ELISA. MAb MT1 reacted with all serotype D-I strains but not with D-II strains, whereas MAb MT2 reacted with both serotype D-I and D-II strains in dotELISA and immunoblot assay. MAb MT3 reacted with all $P$. multocida strains belonging to different capsular serotypes in dot-ELISA. None of the MAbs reacted with other gram-negative bacteria tested, indicating that protein $H$ has a serotype D-I specific epitope and protein $W$ has both serotype and species-specific epitopes. PCR assay was used to identify toxigenic strains of $P$. multocida; $92 \%$ of $P$. multocida strains possess both tox $A$ gene and MAb MT2 reacting epitope, suggesting a strong association between MAb MT2 reacting epitopes and tox $A$ gene. Rapid dot-ELISA with MAb was found to be specific, sensitive and easy to perform and thus suitable for routine serotyping of $\boldsymbol{P}$. multocida serotype $D$ strains which might be potentially pathogenic.
\end{abstract}

\section{Introduction}

Pasteurella multocida serotype D strains have been isolated from cattle, goats, rabbits, pigs, turkeys and man $[1,2]$. Some of the serotype D strains are toxigenic, causing atrophic rhinitis in calves, goats and pigs [3-6] and dermal lesions in poultry [7]. Several tests have been used to detect toxigenic $P$. multocida strains, including the guinea-pig skin test [4], cell culture assay [8], enzyme-linked immunosorbent assay (ELISA) $[6,9]$ and polymerase chain reaction (PCR) assay $[10,11]$. The gene that encodes the toxin of $P$. multocida, tox $A$, has been isolated and sequenced [12]. PCR assay based on toxA gene has been shown to be a highly sensitive and specific assay for identification of toxigenic strains of $P$. multocida $[10,11]$

Indirect haemagglutination (IHA) [13], mouse passive protection [14], gel diffusion precipitin (GDP) [15], co-agglutination [16] and counter-immunoelectrophor-

Received 19 Sept. 1996; accepted 4 Nov. 1996. Corresponding author: Professor K. R. Mittal. esis [17] have been used for serotyping $P$. multocida strains. There are five capsular serotypes, recognised by the IHA test $[13,18]$, and 16 somatic serotypes, recognised by the GDP test [15]. Non-serological tests such as mucopolysaccharidase [2] and acriflavine [19] tests have also been developed for rapid identification of serotypes A, D and F strains of $P$. multocida. Serotyping of $P$. multocida strains by current techniques produces ambiguous results [20]. It is difficult to prepare high-titre antisera against serotypes $A$ and D specific antigens [18]. Numerous strains which remain untypable have also been reported [20-23]. Moreover, these tests are also known to give false-negative results with non-capsulate or less capsulate variants of P. multocida [17]. Thus, a more reliable method for serotyping of $P$. multocida isolates needs to be developed.

$P$. multocida serotype D strains were recently classified into two types (D-I and D-II) based on the electrophoretic mobility of two outer-membrane proteins (OMPs) (proteins $\mathrm{H}$ and $\mathrm{W}$ ) and their reactivities with monoclonal antibodies (MAbs) [24, 25]. The purpose of this investigation was to develop a more 
precise and specific tool for routine typing of serotype D strains and to find out if there is any relationship between the presence of MAb-reacting epitopes and the toxA gene among P. multocida strains.

\section{Materials and methods}

\section{Bacterial strains and culture conditions}

The 55 strains of $P$. multocida representing various serotypes, geographic origins and animal species used in this study are listed in Table 1. P. aerogenes ATCC 27883, $P$. gallinarum ATCC $13360, P$. canis NCTC $11622, P$ sp. $B$ SSI P683 and $P$. SP-g SSI P603, were obtained from R. Mutter, Institut für Mediziniche Mikrobiologie Klinikum der Philipps-Universität Marburg (Lahn), Germany. Haemophilus influenzae ATCC 9006, Actinobacillus lignieresii ATCC 19393, A. pleuropneumoniae, A. suis, Bordetella bronchiseptica, Klebsiella pneumoniae, Escherichia coli K12 143, Salmonella arizona ATCC 13314, Yersinia enterocolitica ATCC 23715, Pseudomonas aeroginosa ATCC 27853, Shigella sonnei ATCC 29930 and Campylobacter jejuni were obtained from the stock culture collection of the Faculté de Médecine Vétérinaire, Université de Montréal, Canada.

A. pleuropneumoniae and $H$. influenzae were grown on chocolate blood agar plates in air with $\mathrm{CO}_{2} 7 \%$. C. jejuni was cultured on blood agar plates in a microaerophilic environment $\left(\mathrm{O}_{2} 5 \%\right)$. P. multocida strains and all the other gram-negative bacteria were cultured aerobically on blood agar plates at $37^{\circ} \mathrm{C}$ for $24 \mathrm{~h}$.

\section{Preparation of OMPs}

P. multocida strains of serotype A $(1662,2100,4062)$, serotype B $(656,5325)$, serotype D $(4065,2153)$, serotype E (4096) and serotype F (4679 and 4218) were disrupted in a French press and Sarkosyl-insoluble OMPs were prepared as described previously $[25,26]$. Sarkosyl-soluble OMPs of $P$. multocida serotypes B 656 and D 2153 were dialysed against Tris- $\mathrm{HCl}(\mathrm{pH}$ 7.8) and were treated with Triton X-100 (Sigma) $1 \%$ $\mathrm{v} / \mathrm{v}$ in the presence of $10 \mathrm{mM} \mathrm{MgCl}_{2}$ at room temperature for $1 \mathrm{~h}$. After centrifugation, the Tritoninsoluble OMP preparation was resuspended in distilled water and stored at $-20^{\circ} \mathrm{C}$. The protein concentration was determined by the method of Bradford [27].

\section{Production of monoclonal and polyclonal antibodies}

Three monoclonal antibodies (MAbs) designated MT1, MT2 and MT3 were produced in BALB/c mice, with OMPs of serotypes D P210 or B 656 of P. multocida as described previously [24]. A MAb produced against Mycoplasma gallisepticum (MAb K1) was used as a negative control in competitive ELISA [28]. Polyclonal antibodies against the $32-\mathrm{kDa}$ OMP (porin $\mathrm{H}$ ) of $P$. multocida were produced in $\mathrm{BALB} / \mathrm{c}$ mice, as described previously [25]. MAbs were purified from ascitic fluid with caprylic acid and ammonium sulphate as described by Ogden and Leung [29]. Proteinase-K and sodium periodate treatments of OMPs were performed as described previously [24].

\section{Epitope analysis by competitive ELISA}

Competitive ELISA was performed as described previously [28], in 96-well microtitration plates coated with Triton-insoluble OMPs of $P$. multocida serotype D 2153 as antigen, to analyse the epitope specificity of MAbs MT2 and MT3. Purified MAb MT2, at a protein concentration of $1 \mathrm{mg} / \mathrm{ml}$, was biotinylated according to the manufacturer's instructions (Biotinylation kit, Amersham). It was used in a reciprocal competitive ELISA at a dilution of 1 in 1000 corresponding to an optical density (OD) of 1.0 at $405 \mathrm{~nm}$. All incubations were at $37^{\circ} \mathrm{C}$ for $90 \mathrm{~min}$, and dilutions and washings were performed in PBS-Tween (PBS-T). Ten-fold serial dilutions of the unlabelled competing homologous and heterologous MAbs were prepared. MAb against $M$. gallisepticum was used as a negative control. One hundred $\mu 1$ of MAbs in PBS-T were added to each well and incubated. After three washings and a further incubation with biotinylated MAb MT2, the plates were washed and incubated with an optimal dilution of streptavidin-peroxidase conjugate (BioRad). Finally, the plates were washed and developed for $30 \mathrm{~min}$ at room temperature in the dark with $o$-phenylenediamine (Sigma). The percentage of competition was calculated by the formula $[100(A-n) / A-B)] . A$ is the OD in the absence of competitor MAb (negative control $\mathrm{MAb}), n$ is the OD in the presence of heterologous competitor, and $B$ is OD in the presence of homologous competitor. For the interpretation of results, $<30 \%$ competition was considered non-competitive, $30-70 \%$ was considered partially competitive and $>70 \%$ was considered fully competitive.

\section{Rapid dot-ELISA}

The spectrum of activity of MAbs with different $P$. multocida strains and other gram-negative organisms was tested by rapid dot-ELISA as described by Achacha and Mittal [30]. A 10- $\mu 1$ volume of optimally diluted boiled cell suspension was spotted on to a nitrocellulose membrane and allowed to dry at room temperature. The membrane was incubated with skim milk $5 \% \mathrm{v} / \mathrm{v}$ in PBS-T before incubation with MAb supernates for $1 \mathrm{~h}$ at room temperature. The blots were washed and incubated with goat anti-mouse horseradish peroxidase conjugate (BioRad) for $1 \mathrm{~h}$ at room temperature and washed. Membranes were developed in 4chloro-1-naphthol substrate (BioRad) for 5-10 min, and the colour reaction was terminated by flooding the membrane with distilled water. Very strong binding, strong binding, distinct binding, weak binding and no binding of MAbs with antigens were recorded as 4+, $3+, 2+, 1+$ and - respectively. 


\section{SDS-PAGE and immunoblot assay}

SDS-PAGE was performed by the method of Laemmli [31] with acrylamide $12 \%$ resolving gels. Immunoblot assay was performed by the method of Towbin [32], as described previously by Vasfi Marandi et al. [25].

\section{Preparation of genomic DNA}

Genomic DNA of 55 strains of $P$. multocida was prepared by the method of Daigle et al. [33]. P. multocida strains were grown in brain-heart infusion broth at $37^{\circ} \mathrm{C}$ overnight. One $\mathrm{ml}$ of overnight culture was centrifuged at $18000 \mathrm{~g}$ for $10 \mathrm{~min}$. The sediment was suspended in $200 \mu \mathrm{l}$ of sterile water and boiled for $10 \mathrm{~min}$ at $100^{\circ} \mathrm{C}$. After centrifugation of the lysate, a $150-\mu 1$ sample of the supernate was stored at $-20^{\circ} \mathrm{C}$ as a template DNA stock.

\section{PCR amplification of toxA gene}

Two oligonucleotide primers with the following sequences were synthesised on a Gene Assembler (Pharmacia LKB Biotechnology Inc.): oligonucleotide 1; 5'-TACTCAATTAGAAAAAGCGCTTTATCTTCC3'; oligonucleotide 2, 5'-TCTACTACAGTTGCTGGTATTTTAAATAT- $3^{\prime}$. Oligonucleotide 1 corresponds to the sense strand of nucleotide positions 1983-2012 and oligonucleotide 2 corresponds to the anti-sense strand of nucleotide position $3212-3183$ of the toxA gene of P. multocida $[11,12]$.

Amplification of DNA was performed in a total volume of $50 \mu \mathrm{l}$ by the method of Nagai et al. [11]. The reaction mixture consisted of $1 \mu \mathrm{M}$ of each oligonucleotide primer, $200 \mu \mathrm{M}$ each of dATP, dCTP, dGTP and dTTP, 1 unit of Taq DNA polymerase (Gibco BRL, Burlington, Canada), $5 \mu \mathrm{l}$ of $10 \times$ reaction buffer $(1.5 \mathrm{mM} \mathrm{MgCl}, 10 \mathrm{mM}$ Tris $\mathrm{HCl}, \mathrm{pH}$ $8.4,50 \mathrm{mM} \mathrm{KCl}$, glycerol $4 \%$ ) and $10 \mu \mathrm{l}$ of sample DNA. The reaction mixture was covered with a drop of mineral oil and was subjected to 25 cycles of $1 \mathrm{~min}$ at $92^{\circ} \mathrm{C}, 1 \mathrm{~min}$ at $55^{\circ} \mathrm{C}$, and $2 \mathrm{~min}$ at $70^{\circ} \mathrm{C}$ in a Thermal Cycler (Perkin Elmer Cetus, Canada). A toxigenic serotype D strain 4-4056 and non-toxigenic serotype A strain X-73 were used as controls. A negative control without DNA was also included in each run. Ten $\mu 1$ of the amplification products were separated by electrophoresis in agarose $1.2 \%$ gels (Gibco BRL), and the DNA fragment was visualised by UV fluorescence after straining with ethidium bromide $0.5 \mu \mathrm{g} / \mathrm{ml}$. A 1-kb DNA ladder (Gibco BRL) was used as a size marker in all gels.

\section{Results}

\section{$W$ protein of $P$. multocida}

Two MAbs designated MT2 and MT3 were produced with OMP preparations of $P$ multocida serotype D P210 and B 656 respectively. In immunoblot assay, both MAbs MT2 and MT3 reacted with a 32-kDa OMP of P. multocida serotype D 2153 (Fig. 1). The epitopes reactive with MAb MT2 were sensitive to treatment with both proteinase $\mathrm{K}$ and sodium periodate whereas those reactive with MAb MT3 were sensitive to treatment with proteinase $\mathrm{K}$ but not sodium periodate. The results of competitive ELISA showed that there was no competition $(<10 \%)$ between the two MAbs MT2 and MT3 (Fig. 2).

\section{SDS-PAGE analysis of $H$ protein of $P$. multocida}

Sarkosyl-insoluble OMPs or whole-cell proteins of 55 strains of $P$. multocida were analysed by SDS-PAGE. Based on the migration of the major OMP (porin $\mathrm{H}$ ), three OMP patterns within serotype A (A-I, A-II and A-III), two within serotype B (B-1 and B-II), two within serotype D (D-I and D-II) and two within serotype F (F-I and F-II) were observed. No heterogeneity was found among three strains of serotype $\mathrm{E}$ tested. Polyclonal antibodies directed against the 32$\mathrm{kDa}$ porin $\mathrm{H}$ of $P$. multocida reacted with the major OMPs of all P. multocida strains tested in immunoblot assay (Fig. 3, Table 1).

\section{Serospecificity of MAbs}

The 55 strains of P. multocida and 17 other gramnegative bacteria were tested for reactivity with MAbs MT1, MT2 and MT3 by dot-ELISA and immunoblot assay. MAb MT1 directed against the 32-kDa porin of $P$. multocida reacted only with serotype D-I strains; $90 \%$ of serotype D strains (D-I and D-II) reacted with MAb MT2. However, two serotype A strains (1702, 2305A) and some of the untypable strains also reacted with MAb MT2. None of the serotype B, E and F strains reacted with MAbs MT1 and MT2. There was $100 \%$ correlation between results obtained with dotELISA and immunoblot assay. MAb MT3 reacted with all 55 strains of $P$. multocida in dot-ELISA. However, three strains $(4399,4096$ and 4679) failed to react in immunoblot assay. MAb MT3 reacted more strongly with serotype D strains than with other serotypes of P. multocida strains in dot-ELISA (Table 1).

MAbs MT1, MT2 and MT3 did not react with other gram-negative bacteria including $P$. aerogenes ATCC $27883, P$. gallinarum ATCC $13360, P$ canis NCTC $11622, P$. sp. $B$ SSI P683, $P$. SP-g SSI P603, $H$. influenzae ATCC 9006, A. lignieresii ATCC 19393, $A$. pleuropneumoniae, A. suis, B. bronchiseptica, $K$. pneumoniae, E. coli $\mathrm{K} 12 \mathrm{HFR}, S$. arizona ATCC 13314, Y. enterocolitica ATCC 23715, Ps. aeruginosa, ATCC 27853, Sh. sonnei, ATCC 29930 and C. jejuni.

\section{PCR amplification of toxA gene}

PCR assay was used to discriminate between toxigenic and non-toxigenic P. multocida strains tested. For PCR amplification, two oligonucleotide primers were chosen on the basis of the sensitivity and specificity obtained when used in PCR. These primers were located around the 1.5-kb HindIII-HindIII fragment of the toxA gene 


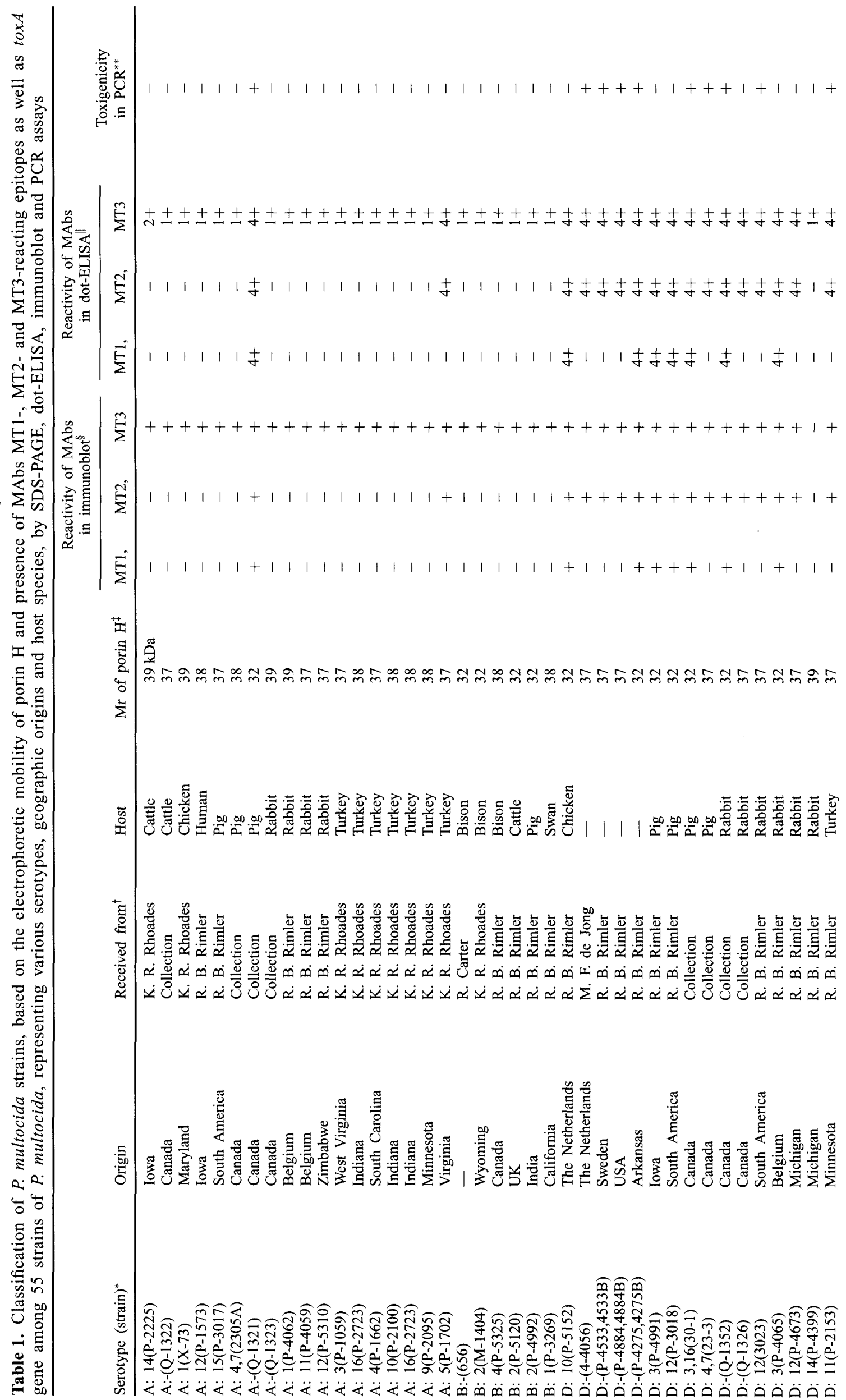




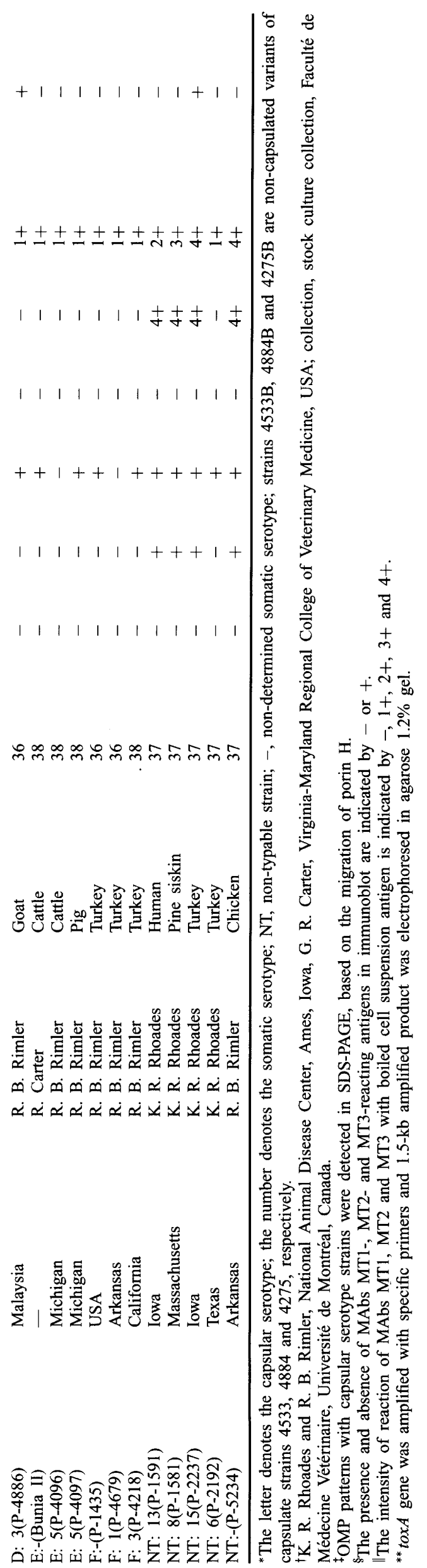




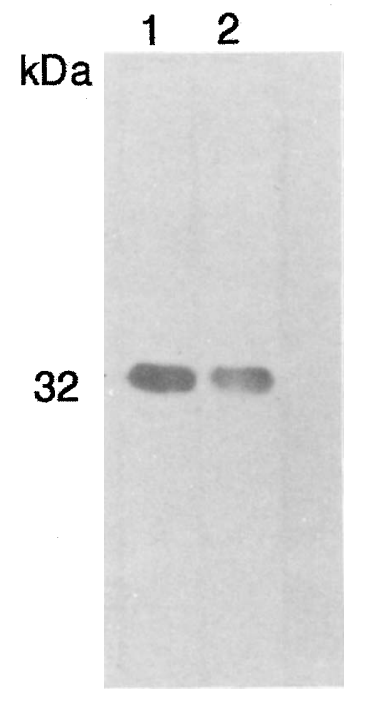

Fig. 1. Reactivities of MAbs MT2 (lane 1) and MT3 (2) with $32-\mathrm{kDa}$ Triton insoluble OMP preparation of $P$. multocida serotype D 2153 in immunoblot assay.

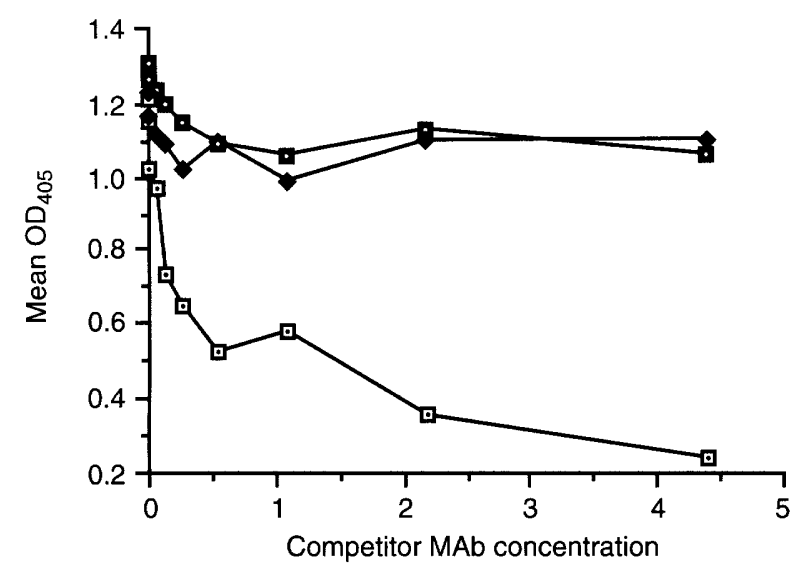

Fig. 2. Epitope analysis of $\mathrm{W}$ protein of $P$. multocida serotype D 2153 by competitive ELISA. Biotinylated MAb MT2 ( $\square)$ was tested in competion with homologous MAb MT3 ( ) and a negative control MAb (K1) ( against $M$. gallisepticum with Triton-insoluble OMP preparation as antigen.

because the amplified product of this fragment has been clearly detected by agarose gel electrophoresis [11]. The tox $A$ gene was detected in $13(65 \%)$ of 20 serotype D, $1(5.6 \%)$ of 18 serotype A and $1(20 \%)$ of five untypable strains of $P$. multocida. The tox $A$ gene was not detected among any of the serotype $\mathrm{B}, \mathrm{E}$ and $\mathrm{F}$ strains of $P$. multocida (Fig. 4). No relationship was found between serotype D-I or D-II strains and presence of toxA gene. However, $92 \%$ of $P$. multocida strains with the toxA gene possessed a MAb MT2reacting epitope (Table 1 ).

\section{Discussion}

Serological diagnosis and vaccination programmes have been used in attempts to control various animal

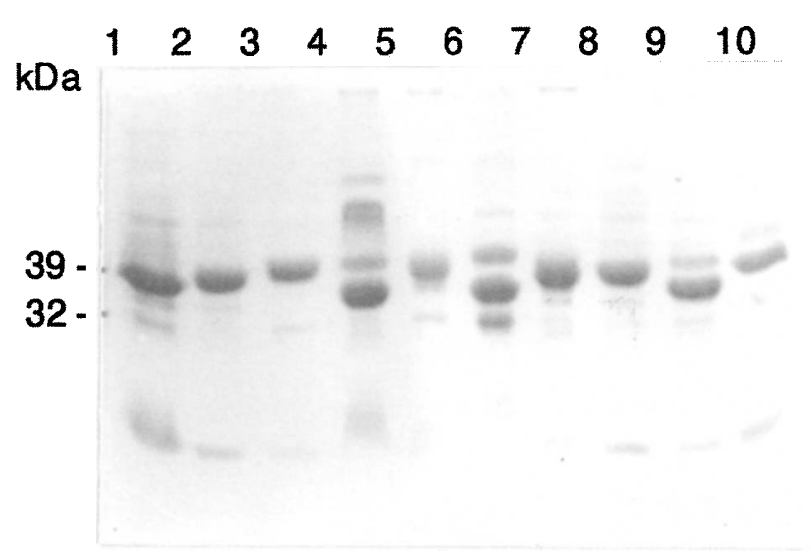

Fig. 3. Electrophoretic mobility of major OMP (porin $\mathrm{H}$ ) of selected $P$. multocida strains. Approximately $15 \mu \mathrm{g}$ of sarkosyl-insoluble OMPs were dissolved in sample buffer by boiling and were separated by SDS-PAGE with a $12 \%$ separating gel. The lanes contain samples of the following strains: 1, serotype A 1662 (type A-I); 2, serotype A 2100 (type A-II); 3, serotype A 4062 (type A-III); 4, serotype B 656 (type B-I); 5, serotype B 5325 (type B-II); 6, serotype D 4065 (type D-I); 7, serotype D 2153 (type D-II); 8, serotype E 4096; 9, serotype F 4679 (type F-I); 10, serotype F 4218 (type F-II).

\section{7}

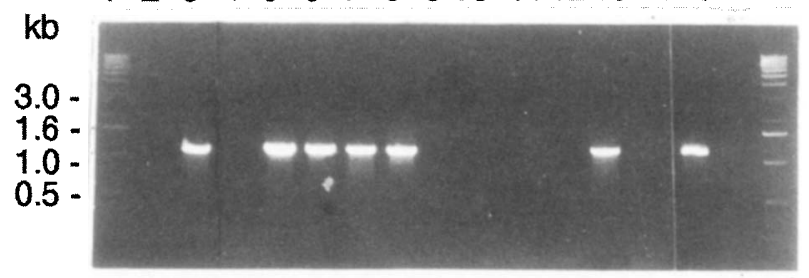

Fig. 4. PCR-amplified toxA gene of selected P. multocida strains detected by electrophoresis in agarose $1.2 \%$ gel. The lanes contain samples of the following strains: 1, molecular size markers; 2 , serotype A $1059 ; 3$, serotype A $2305 \mathrm{~A} ; \mathbf{4}$, serotype A $656 ; \mathbf{5}$, serotype D 4275; 6, serotype D $2153 ; 7$, serotype D $4886 ; 8$, serotype D $3001 ; 9$, serotype D 4673; 10, serotype D 5152; 11, serotype E 4096; 12, serotype F 4679; 13, untypable 2237 strain; 14, serotype A X-73 (negative control); 15, serotype D 4-4056 (positive control); 16, negative control sample without DNA; 17, molecular size markers.

diseases. All these programmes require an extensive knowledge of different serotypes prevalent in the particular region. $P$. multocida is known to be an antigenically heterogeneous pathogen that causes various septicaemic or respiratory diseases in domestic and wild animals and man $[1,2]$. The heterogeneity of this species is evident from the fact that five distinct capsular serotypes $[13,18]$ and 16 somatic serotypes [15] have been identified. Serotyping of $P$. multocida strains by current techniques may produce ambiguous results [20].

It was reported earlier that a MAb (MT2) directed against the $32-\mathrm{kDa}$ OMP (W protein) of $P$. multocida serotype D P210 may be potentially useful for 
identifying serotype D strains [24]. In the present study, another MAb (MT3) was produced against the W protein of $P$. multocida 656 . Results obtained with competitive ELISA and immunoblot assay showed that both MAbs MT2 and MT3 were directed against two distinct epitopes of the $\mathrm{W}$ protein. MAb MT2 reacted with $90 \%$ of serotype D and $80 \%$ of untypable strains in dot-ELISA and immunoblot assay, whereas MAb MT3 reacted with $P$. multocida strains belonging to all serotypes. MAbs MT2 and MT3 did not react with other gram-negative bacteria, suggesting that MAbs MT2 and MT3 were directed against serotype and species-specific epitopes on $\mathrm{W}$ protein, respectively. Both MAbs reacted more intensely with serotype D strains in dot-ELISA than with strains belonging to other serotypes. Seemingly, this may be due to the high expression of the $32-\mathrm{kDa}$ OMP (W protein) in serotype D strains. MAb MT2 recognised both capsulate strains $(4275,4533$ and 4884$)$ and their non-capsulate variants $(4275 \mathrm{~B}, 4533 \mathrm{~B}$ and $4884 \mathrm{~B})$ of serotype $\mathrm{D}$ of $P$. multocida. This observation may be potentially useful especially considering that noncapsulate or less capsulate strains cannot be identified by either IHA or the acriflavine test [17]. MAb-based rapid dot-ELISA was found to be specific, sensitive and easy to perform, for routine serotyping and epidemiological study of both capsulate and non capsulate variants of serotype D strains.

In a previous study, based on the migration of proteins $\mathrm{H}$ and $\mathrm{W}$ in SDS-PAGE and their reactivities with MAbs MT1 and MT2, serotype D strains of $P$. multocida were classified into two groups (D-I and D-II). In this study, two serotype A strains reacted with MAb MT1 or MT2; however, two serotype D strains did not react with MAb MT2. To explain such discrepancy, porin $\mathrm{H}$ of all 55 P. multocida strains was compared in SDS-PAGE as well as in immunoblot assay with monoclonal and polyclonal antibodies. In view of the fact that serotype A strain 1702 bearing $37-\mathrm{kDa}$ porin $\mathrm{H}$ reacted with MAb MT2 and serotype A strain $2305 \mathrm{~A}$ bearing $32-\mathrm{kDa}$ porin $\mathrm{H}$ reacted with both MAbs MT1 and MT2, and the serotype D strains 4886 and 4399 bearing $36-$ and $39-\mathrm{kDa}$ porin $\mathrm{H}$, respectively, failed to react with both MAbs MT1 and MT2, it is suggested that in this serotyping system based on OMP patterns, MAb MT2-reacting serotype A strains may belong to the same serotype as MAb MT2-reacting serotype D strains, whereas serotype D strains which failed to react with MAb MT2 may belong to another serotype.

Some gram-negative bacterial porins are involved in protection against infection [34]. As different OMP patterns, based on the electrophoretic mobility of porin $\mathrm{H}$, were detected among $P$. multocida strains belonging to the same capsular serotype (Fig. 3), it is suggested that the strains with different OMP patterns should be incorporated in a multivalent vaccine for effective protection against pasteurellosis.
To find an eventual relationship between toxigenic strains and those carrying MAbs MT1- or MT2reacting epitopes, the present study proceeded to differentiate toxigenic and non-toxigenic strains by PCR to select the tox $A$ sequence. The tox $A$ gene was detected among serotype D strains, in one serotype A strain and in one untypable strain but not in strains belonging to other serotypes. As $92 \%$ of $P$. multocida strains possessing the toxA gene expressed the MAb MT2-reacting epitope, there seems to be a strong association between the presence of MAb MT2reacting antigen and toxA gene. Kamps et al. [35] reported that some non-toxigenic strains of $P$. multocida might have an incomplete or highly mutated tox $A$ gene. Harel et al. [5] showed a similarity between DNA fingerprinting of toxigenic and some non-toxigenic strains and suggested that the inability of some of the non-toxigenic strains to produce toxin may be related to subtle differences at the chromosomal DNA level.

Although serotype-specific somatic antigens of $P$. multocida have been well characterised and are considered to be lipopolysaccharide (LPS) components of the heat-stable antigens [36], serotypespecific capsular antigens of $P$. multocida have not yet been well characterised. Some investigators have demonstrated that the major antigen involved in the IHA of capsular serotyping was LPS [37], and other workers have shown that capsular polysaccharides, rather than LPS, confer serotype specificity [38]. Rimler et al. [39] showed that the capsule of $P$. multocida serotype $\mathrm{A}, \mathrm{D}$ and $\mathrm{F}$ strains contain mucopolysaccharides that block antigenic determinants involved in IHA test. Recently it was shown that serotype $\mathrm{D}$ specific antigen of $P$. multocida may be a glycoprotein which is masked by capsule [24]. As $90 \%$. of capsular serotype D strains possessed MAb MT2-reacting epitopes which are of glycoprotein nature, it is possible that the antigen involved in the capsular serotyping system may be glycoprotein rather than LPS or capsular polysaccharide. The biological role of serotype D specific antigen has not been studied. However, the $\alpha$-complex antigen of $P$. multocida serotype B described by Prince and Smith [40] was immunogenic for cattle and closely bound to the cell envelope. It probably consists of proteinpolysaccharide complex [41]. A protective antigen extracted from the turkey pathogenic strain of $P$. multocida serotype A contains three protein subunits, as well as one carbohydrate band [42], or a glycoprotein-like antigen [43]. More recently, Rimler [44] reported that the membrane associated proteincarbohydrate antigens of the turkey isolate of $P$. multocida may contribute to immune cross-protection. Further studies are needed to demonstrate antigenic relationships between $32-\mathrm{kDa}$ serotype $\mathrm{D}$ specific glycoprotein (W protein) and protective proteinpolysaccharide antigens described for serotypes A and $\mathrm{B}$ strains of P. multocida. 
We acknowledge with gratitude the gifts of $P$. multocida and other Pasteurella strains from R. B. Rimler, G. R. Carter, M.F. de Jong and R. Mutter. We thank also C. Forget for help with the PCR experiment.

\section{References}

1. Donnio PY, Avril JL, Andre PM, Vaucel J. Dermonecrotic toxin production by strains of Pasteurella multocida isolated from man. J Med Microbiol 1991; 34: 333-337.

2. Rimler RB. Presumptive identification of Pasteurella multocida serogroups $\mathrm{A}, \mathrm{D}$ and $\mathrm{F}$ by capsule depolymerisation with mucopolysaccharides. Vet Rec 1994; 134: 191-192.

3. Baalsrud KJ. Atrophic rhinitis in goats in Norway. Vet Rec 1987; 121: 350-353.

4. de Jong MF, Oei HL, Tetenburg GJ. AR-pathogenicity tests for Pasteurella multocida isolates. Proc IPVS Congr 1980; 6: 119.

5. Harel, J, Côté S, Jacques M. Restriction endonuclease analysis of porcine Pasteurella multocida isolated from Quebec. Can $J$ Vet Res 1990; 54: 422-426.

6. Kamp EM, ter Laak EA, de Jong MF. Atypical Pasteurella multocida strains producing a toxin similar to the dermonecrotic toxin of Pasteurella multocida subspecies multocida. Vet Rec 1990; 126: 434-437.

7. Rhoades KR, Rimler RB. Virulence and toxigenicity of capsular serogroup D Pasteurella multocida strains isolated from avian hosts. Avian Dis 1990; 34: 384-388.

8. Rutter JM, Luther PD. Cell culture assay for toxigenic Pasteurella multocida from atrophic rhinitis of pigs. Vet Rec 1984; 114: 393-396.

9. Foged NT, Nielsen JP, Pedersen KB. Differentiation of toxigenic from nontoxigenic isolates of Pasteurella multocida by enzyme-linked immunosorbent assay. J Clin Microbiol 1988; 26: 1419-1420.

10. Kamp EM, Bokken GCAM, Vermeulen TMM et al. A specific and sensitive PCR assay suitable for large-scale detection of toxigenic Pasteurella multocida in nasal and tonsillar swabs specimens of pigs. $J$ Vet Diagn Invest 1996; 8: 304-309.

11. Nagai S, Someno S, Yagihashi T. Differentiation of toxigenic from nontoxigenic isolates of Pasteurella multocida by PCR. $J$ Clin Microbiol 1994; 32: 1004-1010.

12. Buys WECM, Smith HE, Kamps AMIE, Kamp EM, Smits MA. Sequence of the dermonecrotic toxin of Pasteurella multocida ssp. multocida. Nucleic Acids Res 1990; 18: 28152816.

13. Carter GR. Studies on Pasteurella multocida. I. A haemagglutination test for the identification of serological types. Am J Vet Res 1955; 16: $481-484$.

14. Carter GR. Correlation between haemagglutinating antibody and mouse protection in antipasteurella (Pasteurella multocida) sera. Can J Microbiol 1964; 10: 753-756.

15. Heddleston KL, Gallagher JE, Rebers PA. Fowl cholera: gel diffusion precipitin test for serotyping Pasteurella multocida from avian species. Avian Dis 1972; 16: 925-936.

16. Rimler RB. Coagglutination test for identification of Pasteurella multocida associated with hemorrhagic septicemia. $\mathrm{J}$ Clin Microbiol 1978; 8: 214-218.

17. Chengappa MM, Carter GR, Bailie WE. Identification of type D Pasteurella multocida by counterimmunoelectrophoresis. $J$ Clin Microbiol 1986; 24: 721-723.

18. Rimler RB, Rhoades KR. Serogroup F, a new capsular serogroup of Pasteurella multocida. J Clin Microbiol 1987; 25: $615-618$.

19. Carter GR, Subronto P. Identification of type D strains of Pasteurella multocida with acriflavine. Am J Vet Res 1973; 34: 293-294.

20. Wilson MA, Morgan MJ, Barger GE. Comparison of DNA fingerprinting and serotyping for identification "." of avian Pasteurella multocida isolates. J Clin Microbiol 1993; 31: 255-259.

21. Lu Y-S, Gerrity LW, Affendis SJ, Watkins L, Pakes SP. Distribution of a monoclonal antibody-recognized protective protein immunogen on the outer membranes of Pasteurella multocida rabbit isolates. J Clin Microbiol 1988; 26: 13261330.

22. Magyar T, Rimler RB. Detection and enumeration of toxinproducing Pasteurella multocida with a colony-blot assay.
$J$ Clin Microbiol 1991; 29: 1328-1332.

23. Manning PJ. Naturally occurring Pasteurellosis in laboratory rabbits: chemical and serological studies of whole cells and lipopolysaccharides of Pasteurella multocida. Infect Immun 1984; 44: 502-507.

24. Vasfi Marandi M, Mittal KR. Identification and characterization of outer membrane proteins of Pasteurella multocida serotype D by using monoclonal antibodies. J Clin Microbiol 1995; 33: 952-957.

25. Vasfi Marandi M, Dubreuil JD, Mittal KR. The $32 \mathrm{kDa}$ major outer-membrane protein of Pasteurella multocida capsular serotype D. Microbiology 1996; 142: 199-206.

26. Vasfi Marandi M, Mittal KR. Characterization of an outer membrane protein of Pasteurella multocida belonging to the OmpA family. Vet Microbiol 1996; 53: 303-314.

27. Bradford MM. A rapid and sensitive method for the quantitation of microgram quantities of protein utilizing the principle of protein-dye binding. Anal Biochem 1976; 72: 248-254.

28. Kheyar A, Reddy SK, Silim A. The $64 \mathrm{kDa}$ lipoprotein of Mycoplasma gallisepticum has two distinct epitopes responsible for haemagglutination and growth inhibition. Avian Pathol 1955; 24: $55-68$.

29. Ogden JR, Leung K. Purification of murine monoclonal antibodies by caprilic acid. $J$ Immunol Methods 1988; 111: 283-284

30. Achacha M, Mittal KR. Production and characterization of monoclonal antibodies against Serpulina hyodysenteriae and $S$. innocens and their use in serotyping. J Clin Microbiol 1995; 33: 2519-2521.

31. Laemmli UK. Cleavage of structural proteins during the assembly of the head of bacteriophage T4. Nature 1970; 227: $680-685$.

32. Towbin H, Staehelin T, Gordon J. Electrophoretic transfer of proteins from polyacrylamide gels to nitrocellulose sheets: procedure and some applications. Proc Natl Acad Sci USA 1979; 76: 4350-4354.

33. Daigle F, Harel J, Fairbrother JM, Lebel P. Expression and detection of pap-, $s f a-$, and afa-encoded fimbrial adhesin systems among uropathogenic Escherichia coli. Can J Microbiol 1994; 40: 286-291.

34. Murphy, TF, Bartos LC. Human bactericidal antibody response to outer membrane protein P2 of nontypeable Haemophilus influenzae. Infect Immun 1988; 56: 2673-2679.

35. Kamps AMIE, Buys WECM, Kamp EM, Smits MA. Specificity of DNA probes for the detection of toxigenic Pasteurella multocida subsp. multocida strains. J Clin Microbiol 1990; 28: 1858-1861.

36. Rimler RB. Comparisons of Pasteurella multocida lipopolysaccharides by sodium dodecyl sulfate-polyacrylamide gel electrophoresis to determine relationship between group $B$ and $E$ hemorrhagic septicemia strains and serologically related group A strains. J Clin Microbiol 1990; 28: 654-659.

37. Carter GR, Rappay DE. A hemagglutination test employing specific lipopolysaccharide for the detection and measurement of pasteurella antibodies to Pasteurella multocida. $\mathrm{Br}$ Vet $J$ 1963; 119: 73-77.

38. Penn CW, Nagy LK. Capsular and somatic antigens of Pasteurella multocida types B and E. Res Vet Sci 1974; 16: 251-259.

39. Rimler RB, Register KB, Magyar T, Ackermann MR. Influence of chondroitinase on indirect hemagglutination titers and phagocytosis of Pasteurella multocida serogroups A, D and F. Vet Microbiol 1995; 47: 287-294.

40. Prince GH, Smith JE. Antigenic studies on Pasteurella multocida using immunodiffusion techniques. III. Relationships between strains of Pasteurella multocida. J Comp Pathol 1966; 76: $321-332$.

41. Namioka S. Pasteurella multocida. Biochemical characteristics and serotypes. In: Bergan T, Norris JR (eds) Methods in microbiology, 10. London, Academic Press, 1978: 271-292.

42. Syuto B, Matsumoto M. Purification of a protective antigen from a saline extract of Pasteurella multocida. Infect Immun 1982; 37: 1218-1226.

43. Srivastava KK, Foster JW. Characterization of an immunogenic fraction of Pasteurella multocida culture filtrates. Can J Microbiol 1976; 23: 197-201.

44. Rimler RB. Partial purification of cross-protection factor (s) from Pasteurella multocida. Avian Dis 1994; 38: 778-789. 